\title{
EL ÓRGANO DE CONTROL EXTERNO (OCE) COMO MOTOR DE CAMBIO HACIA LA MEJORA DE LA EFICIENCIA DEL SECTOR PÚBLICO
}

\author{
Tesista: \\ Alicia Zulema Escudero \\ Director de Tesis: \\ Pedro Enrique Andrieu
}

\section{E IDENT I FICACIÓN DEL PROBLEMA}

Ante el cuestionamiento de la comunidad acerca de la falta de eficiencia también de eficacia, equidad y calidad de las instituciones del Estado en su accionar -como necesaria contrapartida de la coacción, ejercida a través de la imposición y la regulación, entre otras-, que no tiene cómo iniciar acciones para resarcirse del daño que puede causarle individualmente el mal manejo de los fondos públicos, cabe preguntarse ¿qué rol desempeña el Órgano de Control Externo (OCE) en la mejora del Sector Público?

Los posibles "puntos de fuga", en el accionar de dichas instituciones, son dos: Riesgo de acción antijurídica y Riesgo de acción ineficaz.

El administrador público se enfrenta a problemas tanto dóciles (sencillos de definir) como perversos (sin soluciones definidas, y cuyas respuestas, solo temporales e imperfectas, pueden ocasionar otros problemas); tales problemas requieren de la comunidad ser resueltos con eficacia, eficiencia, equidad y calidad. Para ello debe ejercer una acción administrativa responsable compuesta de tres aspectos que se encuentran en constante tensión: profesional, político y personal.

Esta acción administrativa y la responsabilidad consecuente serán evaluadas y/o juzgadas en distintas dimensiones: desde la óptica tanto de los poderes Administrador, Legislativo, Judicial, de los Órganos de Control Externo (OCE), como de las Instituciones del Estado y del ciudadano ya sea en forma individual o agrupado -entre otras- en Organizaciones No Gubernamentales (ONG), profesionales, empresariales, sindicales .

Si el tratamiento -evaluación y/o juzgamiento- desde la óptica del OCE se efectúa con responsabilidad profesional, política y personal, podrá convertirse en motor de cambio 
hacia la mejora del Sector Público.

Se ha considerado que los siguientes aspectos han de influir en la construcción del escenario que permita a los OCE actuar en el sentido indicado:

- Voluntad de control,

- Capacidad del controlador para evaluar la acción administrativa,

- Información acerca de la acción administrativa que permita su evaluación,

- Mecanismos de corrección y/o sanción de la acción administrativa y de la conducta de los administradores.

\section{OBJETIVO}

En cada país o región supra o subnacional, los Órganos de Control Externo se han organizado en base a dos líneas de pensamiento: la que se ha dado en llamar anglosajona (Inglaterra, Irlanda, los Estados Unidos de América, Suiza, Dinamarca, Suecia, Chile, Bolivia, Perú,

veniente de Europa continental o latina (España, Francia, Bélgica, Alemania, Italia, Mercado Común Europeo -ahora Unión Europea-, Brasil, Paraguay, Uruguay y otros).

El propósito de esta investigación es explorar el aporte de dichas líneas de pensamiento en el área de control, con relación a los cuatro aspectos mencionados precedentemente, a fin de construir el escenario que facilite a los OCE evaluar y/o juzgar la acción administrativa y la responsabilidad consecuente de los administradores públicos, para, de esa manera, convertirse en uno de los motores de cambio hacia la mejora del Sector Público.

\section{METODOLOGÍA}

Se exploró la bibliografía a fin de:

- Efectuar una breve reseña de las líneas de pensamiento anglosajona y latina (Capítulo II).

- Identificar el aporte de cada línea de pensamiento a los cuatro aspectos seleccionados (Capítulo III).

- Señalar, de dichos aportes, los aspectos que favorecen o limitan la acción de los OCE (Capítulo IV).

- Construir el escenario que propicie un accionar responsable de los OCE en la evaluación y/o juzgamiento de la acción administrativa y la responsabilidad consecuente.

\section{RESULTADOS PRINCIPALES}

Con el aporte de las dos líneas de pensamiento en base a las cuales se han organizado los OCE -consideradas no excluyentes, sino, por el contrario, complementarias-, se ha construido el escenario que propicia a aquellos convertirse en motor de cambio hacia la mejora del Sector Público y que tendrá en consideración los siguientes aspectos:

- El fortalecimiento de los OCE, a través del ámbito normativo, hace posible que sus integrantes actúen de manera imparcial y que su accionar no sea utilizado por parte del Poder Legislativo, en clave meramente partidista o técnica.

- El mantenimiento de un programa de capacitación permanente, con su pertinente evaluación, permite a los OCE enfrentarse con sólidos conocimientos a las complejas actividades que deberá evaluary/o juzgar, dado, especialmente, el avance de la tecnología, en todas las áreas a auditar.

- La coordinación entre las distintas instituciones de control externo nacional, provincial y municipal evita duplicaciones o vacíos de control.

- La información oportuna, confiable y suficiente es una pieza clave en el proceso de evaluación de la acción administrativa, para efectuar, temporáneamente, la corrección de desvíos y/o sanción de la conducta de los administradores.

- La auditoría de gestión e integral permite la evaluación de la acción administrativa en cuanto al uso eficiente y eficaz del Tesoro Público y de su impacto en el medio, en términos de equidad y calidad. 
- La elaboración de presupuestos que contengan programas con objetivos, metas y normas de calidad claramente establecidos facilita la evaluación de los resultados de la gestión.

- La actuación de los servicios jurídicos, tanto en su función de asesoramiento como en su participación en juicios representando al Estado, constituye un área de riesgo, y resulta conveniente su evaluación.

- El reforzamiento del control interno es imprescindible en tanto es la base de sustentamiento del accionar de los OCE.

- La elaboración de programas de fiscalización que trasciendan organizaciones y gestiones concretas y se refieran a grandes áreas del Sector Público propicia, con sus conclusiones y recomendaciones, debates políticos sobre modelos de organización, gestión y control interno del sector.

- La unificación de normas contables, a través de acuerdos técnicos y políticos, es beneficiosa para la Cuenta General de Ejercicio como instrumento de evaluación y control de la gestión gubernamental.

- El mantenimiento o la implementación de la jurisdiccionalidad -agilizando su mecanismo, como instancia previa a la remisión a la justicia, en aquellos casos relacionados con la falta de rendición de cuentas, documentación no justificativa de la inversión o probable perjuicio al erario, atento a su bajo costo e informalidad administrativa- evita los plazos y las costas de un proceso judicial que podría culminar con sentencia en contra del Estado.

- El mantenimiento o implementación del control de 4to. grado, o sea el del insumo valori-zado -el gasto- como primer escalón para ir "subiendo" al de 3er. grado (resultado de la acción), 2do. (costo de la acción) y 1ero. (impacto de la acción en la necesidad), en la medida que se disponga de la pertinente información.

- La evaluación de la decisión administrativa previa a su ejecución, en forma selectiva, es aún una discusión respecto de que, un con- trol externo previo, significaría incurrir en cogestión, pero, ¿en qué momento se debería efectuar el control externo de aquellas decisiones que, una vez ejecutadas, podrían generar perjuicios irreparables al erario, resultando en consecuencia el OCE copartícipe no ya de la gestión sino del perjuicio ocasionado?

- La implementación, mantenimiento y/o actualización de multas, especialmente, por falta de rendición de cuentas o morosidad en su presentación.

- Una fluida comunicación entre los tres poderes facilita que éstos corrijan las fallas que se detectan en su control interno.

- El desarrollo de un control externo circular, a través de la intervención del OCE en la evaluación de la implementación de un presupuesto y en la confección del presupuesto siguiente.

- La información por áreas -concisa y relevante al Poder Legislativo sobre la marcha de la gestión administrativa, mientras ella se produce, a través, por ejemplo, de informes cuatrimestrales- permite su evaluación y un seguimiento de cerca del accionar del OCE.

- El conocimiento de los informes del OCE por parte de la opinión pública, habiendo dado a los auditados, previamente, la posibilidad de efectuar sus descargos, y promover la participación ciudadana.

\section{CONCLUSIONES}

Construido el escenario e independientemente de la forma en que el Órgano de Control Externo se organice - para cuya elección sería conveniente prestar atención tanto a las tradiciones como a las cambiantes realidades sociopolíticas regionales, nacionales e internacionales y tener presente que el control ha de ser tanto como sea necesario y tan poco como sea posible-, debería tratarse de aprender de la experiencia.

Por ello, se considera prudente mantener o implementar normativamente un control cu- 
yos objetivos sean tanto correctivos como sancionadores, y que sea la experiencia la que permita su flexibilización en la práctica.

Ello requerirá de los integrantes de los OCE el ejercicio de una responsabilidad basada en la autonomía enraizada, en virtud de la cual, a través de la combinación, en apariencia contradictoria, del aislamiento weberiano y una intensa inmersión en la problemática de los administradores, los controladores puedan tener una eficaz participación y actuar como uno de los motores de cambio hacia la mejora del Sector Público.

Para lograrlo deberá operarse un cambio individual y de cultura organizacional de forma tal que el espíritu de quienes integran los órganos de control externo se impregne de la necesidad de búsqueda de mecanismos mediante los cuales se brinde uno de los servicios fundamentales al pueblo de la Nación: el resguardo del Tesoro Público.

El controlador, amparado en su juicio personal, resultante del equilibrio de su responsabilidad profesional, política y personal, evaluará la acción administrativa y la conducta de los administradores, y detectará las zonas de riesgo y los posibles puntos de fuga y, en base a ello, irá intensificando o flexibilizando el control de modo de considerar tanto el riesgo de antijuricidad como el de acción ineficaz.

\section{BIBLIOGRAFÍA}

Harmon, Michael M. y Mayer, Richard T. (1999): Teoría de la organización para la Administración Pública. México, Fondo de Cultura Económica.

Petrei, Humberto (1997): Presupuesto y control. Pautas de reforma para América Latina. Banco Interamericano de Desarrollo.

Petrei, Romeo (1996): El control de la hacienda pública en América Latina. Un estudio comparativo. Córdoba, Argentina: Ediciones EUDECOR.

Nadler, D. A.; Gerstein, M. S.; Shaw, R. B. y asociados: Arquitectura organizativa.

Schein, Edgar H. (1994): Psicología de la organización. México: Prentice Hall Hispanoamérica SA.

Robbins, Stephen P. (1987): Comportamiento organizacional. México: Prentice Hall Hispanoamérica SA.

Etzione, Amitai: Organizaciones Modernas. Macchi. Buenos Aires.

Pontificia Universidad Católica Argentina. Anuario. Facultad de Ciencias Económicas del Rosario. Rosario, Argentina, 1999. 
Cardón, Rubén C. A. y Castiglioni Antonio V. (1988): Temas de Tribunales de Cuentas. Santiago del Estero: El Liberal.

Cortés de Trejo, Lea C.: Tribunales de Cuentas, auditorías generales y algo más.

Boletín informativo del Secretariado Permanente de Tribunales de Cuentas.

Revista El Control Público. Publicación del Secretariado Permanente de Tribunales de Cuentas.

Constitución Nacional de la República Argentina.

Constituciones Provinciales de la República Argentina.

Ley Nacional 24156 de Administración Financiera.

Leyes Orgánicas de Tribunales de Cuentas de las Provincias de la República Argentina.

Ley 24127. Premio Nacional a la Calidad para el Sector Público.

Proyecto de Ley de Administración Financiera de la Provincia de Santa Fe. 